\title{
A Methodology to Identify New Service Opportunities Based on Equipment Lifecycle
}

\author{
Shaun West ${ }^{1, *}$, Adriano Pascual ${ }^{2}$ \\ ${ }^{1}$ Business Engineering \& Innovation Department, Lucerne University of Applied Sciences and Arts, Switzerland \\ ${ }^{2}$ Engineering Business Management Department, Coventry University, United Kingdom
}

Copyright $\mathrm{O} 2016$ by authors, all rights reserved. Authors agree that this article remains permanently open access under the terms of the Creative Commons Attribution License 4.0 International License

\begin{abstract}
This paper describes a methodology that has been used successfully to assist two manufacturers in identifying opportunities for developing services based on the equipment they sell. Manufacturing firms often experience difficulties to understand the service needs of their customers over the lifecycle of their product. This paper assists those companies to identify new service opportunities by combining the approaches of product lifecycle and total cost of ownership with the customer value proposition into a new and holistic methodology. This new methodology was tested with in workshop participants of investment good companies first on a generic example of a car and afterwards applied to their specific products. The first case allowed the participants to work together and develop an understanding of the new tools. Key findings of the generic stage were the perception of how product-services systems are viewed by the owner rather than the supplier of a piece of equipment. The second case built upon their newly acquired servitization understanding allowing the participants to consider how their customer's needs change during the full operational life of the equipment. Using this combined visual approach based on the 'customer value proposition canvas', 'product lifecycle' and 'total cost of ownership' allowed to identify new service. This allows manufacturers to identify, create and deliver customer value over the full operational life of the equipment. The approach was experimental, but discussions with the teams and their managers suggested it proved useful in helping them to discover new/hidden services for their products.
\end{abstract}

Keywords Product-service System, Equipment Lifecycle, Customer Value Proposition, Total Cost of Ownership, Visualization

\section{Introduction}

Neely (2007) states that manufacturing in developed countries is under intense pressure from new competitors and that manufacturers cannot longer compete purely on cost. He also views servitization as a way to compete through diversification against these challengers and a way to hold or even grow the profitability. Cohen et al. (2006) confirms that services have, in general, higher profitability than the core manufacturing businesses.

Even though the concept of servitization appears to be essential for the survival of today's manufacturing companies, it seems that it is not fully established. Manufacturing firms often have difficulty understanding the service needs of their customers for the full operational life of the equipment supplied (Baines and Lightfoot, 2013 and Fischer et al., 2012). To investigate this problem, three workshops were held with two different firms. During the workshops the equipment lifecycle was considered using on the total cost of ownership approach (Ellram, 1993) and the customer value proposition (Anderson and Narus, 1999 and Osterwalder 2014). The objective of this approach was to identify new services and associated customer value propositions. The use of these tools was as a prototype for encouraging a Service Design Thinking (Stickdorn and Schneider, 2012) approach to increase the openness and creativity of the participants.

The main sections in this paper include a literature review where the two tools are introduced; a methodology section describing how the 3 workshops sessions were arranged, a section that describes and discusses the results; and closes with sections for conclusions and recommendations.

\section{Literature Review}

\subsection{Total Cost of Ownership Models to Identify Equipment Lifecycles}

The total cost of ownership (TCO), sometimes called lifecycle costing, is a cost management methodology that analyses all costs associated with the equipment during its life. Ellram (1993) describes this for capital equipment and 
recommends that all of the lifecycle costs should be considered, including the equipment disposal. Wynstra (2005) takes this a step further saying that the costs drivers or tasks, which the customer (or the owner or operator) is exposed to, should also be included. Wynstra (2005) also provides a supporting and updated framework that identified some of the activities and when in the lifecycle the different phases occurred. Hurkens and Wynstra (2004), takes the TCO model a further step forward by considering the total value of ownership concept (TVO). The relationship between price, TCO and TVO is shown in Figure 1 and is similar to the modelling approach used in project finance where all costs and revenue streams are considered, albeit on a single piece of equipment basis.

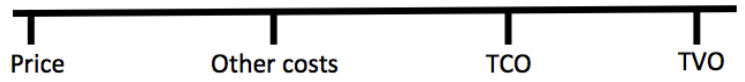

Figure 1. Evolution of cost models identified by Hurkens and Wynstra (2004)

Singh and Dunn (2008) describes how the operational life of the equipment can be broken down into distinct activities (or cost drivers): planned and routine maintenance, emergency-breakdowns and repairs, and renewal. This breakdown would include all necessary spare parts that may be required during the operational life of the equipment. Singh and Dunn's (2008) list does not include other activities e.g. leasing, financing or rental activities that may be required, whereas the TVO model of Hukens (2004) could also be thought to include these 'financial' value adding activities. Stockgi (2012) presented the generic equipment lifecycle in a visual form shown in Figure 2 although it fails to identify CAPEX (or capital expenditure) related costs during the operational period focusing purely on OPEX (or operational expenditure) costs.

Understanding all the components or cost drivers for the total cost of ownership provides the supplier with a detailed understanding of costs and possible value added opportunities (Wynstra, 2005). Wynstra's (2005) paper also confirmed that only a few suppliers identify value-added services on the basis of TOC throughout the lifecycle of the equipment.

\subsection{The Use of Value Propositions to Describe Customer Value}

Anderson et al. (2006) makes it clear that suppliers should focus on value rather than simply costs and in particular, create clear customer value propositions for the products and services that are offered. This should be either at a customer level or a segment level. Osterwalder, et al. (2014), also acknowledges the importance of understanding the customer for a successful value proposition. He provides a visual design-oriented approach to create the value proposition that Anderson et al. (2006) recommends. According to Osterwalder customers will experience pains and gains when performing a task or a job. A successful value proposition will increase the gains for a customer and reduce their pains. However, it is important to prioritize both the pains and gains and to address only the most relevant for the customer. A combination of Anderson et al. and Narus's (1999) concepts of price paid and the value received is compared with a modified version of Osterwalder's customer value proposition. In this modified version, the value creation/destruction is compared to the gains and pains (Figure 3).

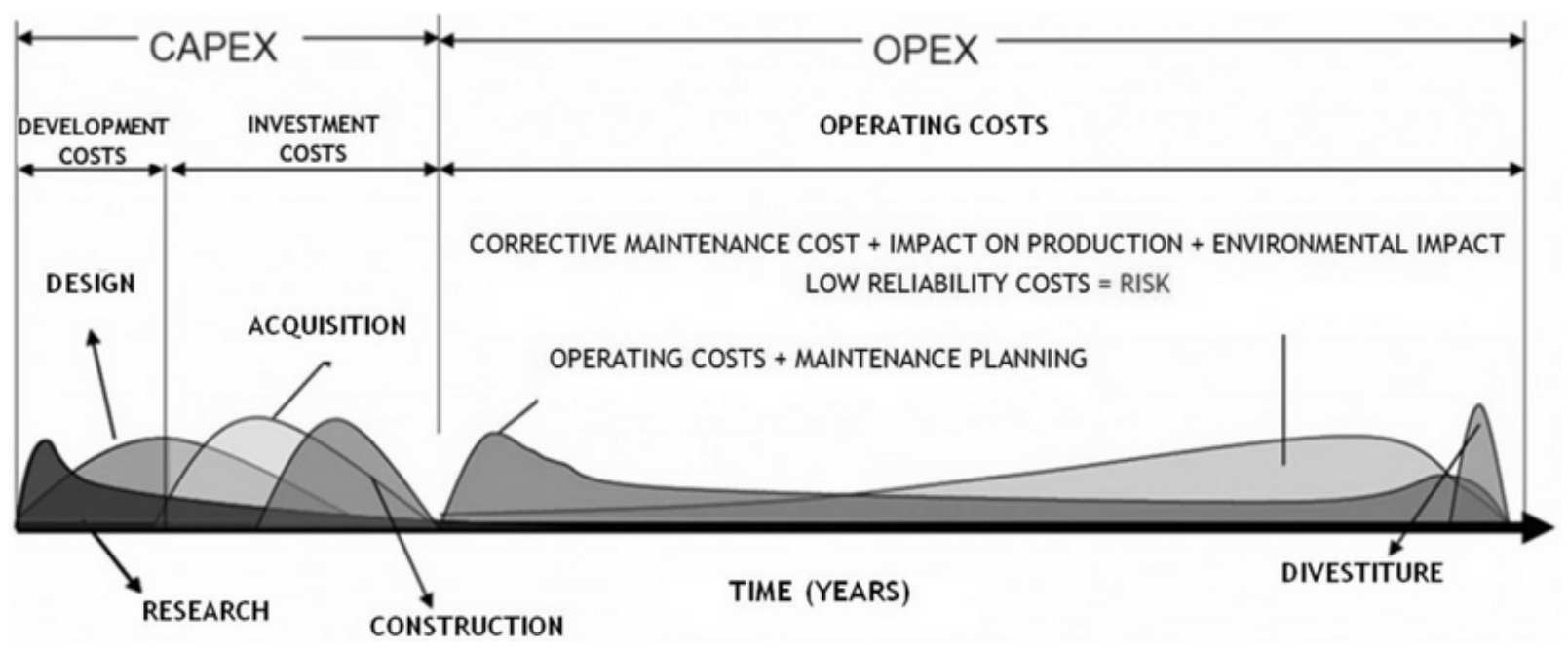

Figure 2. CAPEX and OPEX on a generic lifecycle (Stockgi, 2012) 


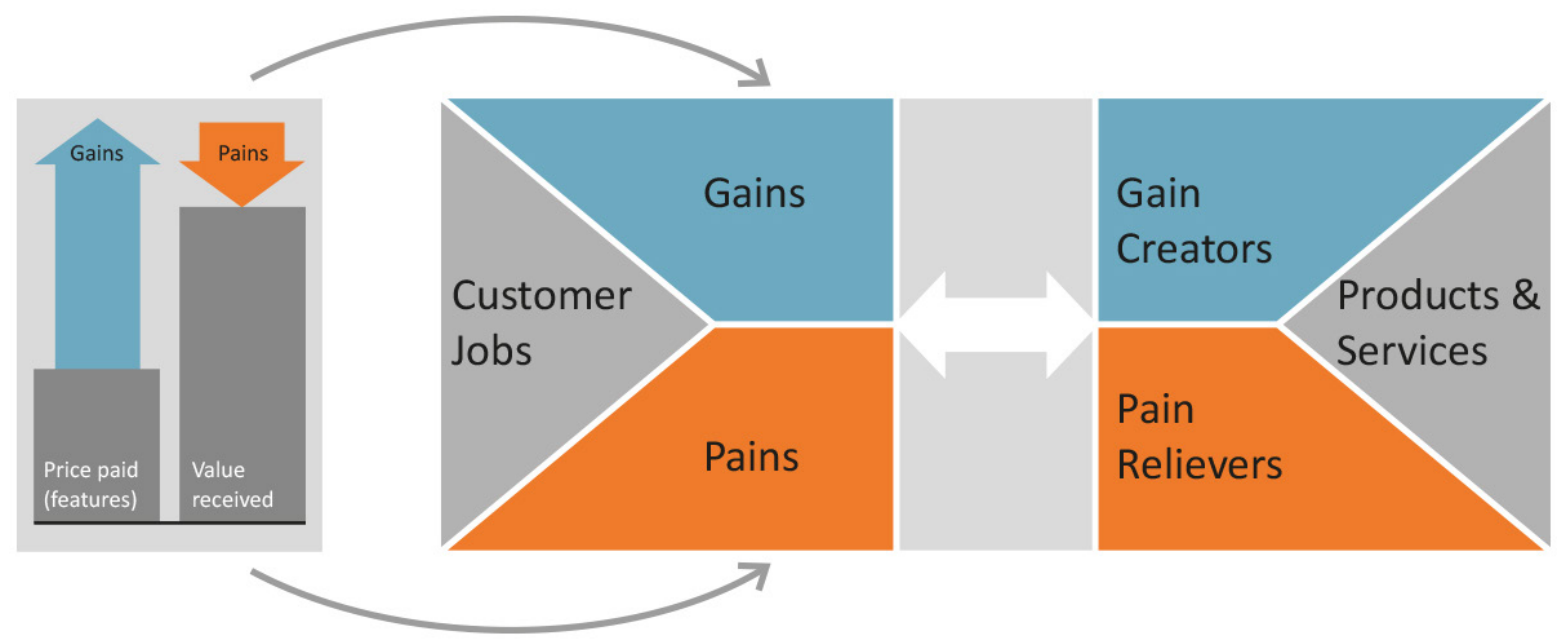

Figure 3. Value proposition design based on Anderson and Narus (1999) and Osterwalder, et al. (2014)

\subsection{Best Practice in Workshops}

Workshop success can be improved by using structured visual approaches to decision making according to Stickdorn and Schneider (2012). Further analysis can (and in some cases must) be completed outside of the workshop with the full team or part of the team reforming to review further the analysis. Stickdorn and Schneider (2012) recommends that multi-disciplinary teams should be used in a workshop environment to ensure that wide ranges of inputs are captured and so that commonly held assumptions can be challenged. Where possible a 'user' should also be included in the discussions.

\subsection{Hypothesis under Investigation}

This paper will describe a methodology that was developed to allow manufacturers to start to visualise clearly how their customers use the equipment that they have supplied enabling their teams to discover new services and then to create the customer valuation. Use of the car as an example provided a neutral platform allowing them to become accustomed to the tools before moving into their own products and the services required to support them.

\section{Methodology}

Two different firms were selected for the workshops to allow prototyping; the participation of the firms was needed to provide direct feedback of the applicability of the tools being tested. Both workshops were introduced in a similar way to reduce the variability, first with some theory and then a test case based on the car. They were then provided with the opportunity to use the tools based on products that they offer to their customers. A log was made of the sheets created and a list of new ideas to work on at a later stage.

\subsection{Selection of the Teams and Team Members}

Mixed teams were used for the workshops to provide a wider range of inputs with the expectation that fewer issues were likely to be missed out as a result. Selection of the teams was based on the brief: "teams should be interdisciplinary and should include frontline employees such as, service engineers, field sales, or even customers themselves.".

\subsection{Workshop Structure}

The objective of the workshops was to bring the product and the service sides of the business together to refocus on the product service system from the point of view of their customers. From this there was an expectation that new service opportunities and product improvements could then be identified.

The generic agenda for each of the workshops was:

1. Introduction

- To ensure a minimal level of service understanding.

- To share information on service know-how.

2. Car example

- To provide a 'safe' environment to learn and understand the cradle-to-grave equipment lifecycle and to develop a customer value proposition for one important activity.

3. Own product

- To provide a cradle-to-grave equipment lifecycle.

- To provide a customer value proposition for one activity.

The agenda was designed so that everyone would have at least a limited understanding of services and opportunities to work together. The teams were instructed to work together using Post-it's in a creative risk-free environment based on the approach described by Stickdorn and Schneider (2012). This was deliberately used to allow all participants to take an active role in the process. Poster-templates were also used so that the team members could actively engage in the workshop. A blank template was used for both the car and 
the company-specific equipment lifecycle. Figure 4 shows an example of the complete lifecycle of a car using the poster template from the workshops. Figure 5 provides an example of the value proposition for the car associated with the modification of the car from petrol to biogas.

\section{Results and Discussion}

As described by Neeley (2007) and Cohen et al. (2006) it is essential for manufacturing companies to understand the service needs of their customers. Without this understanding they will offer the wrong services with little value addition or no service at all. The combination of the two tools presented will allow suppliers to gain a more comprehensive image of their customers and to align their service offer accordingly. This section describes and discusses the results from three workshops using the cradle-to-grave equipment lifecycle combined with the customer value proposition.

The two companies were from very different segments with different specific products and services (Table 1). Nevertheless, both were able to use the tools to identify new services for their customers. The lifecycle helped them to identify appropriate points in time for the injection of the new services (including options for end of life) and the value proposition design allowed them to align their ideas with their customer's needs.

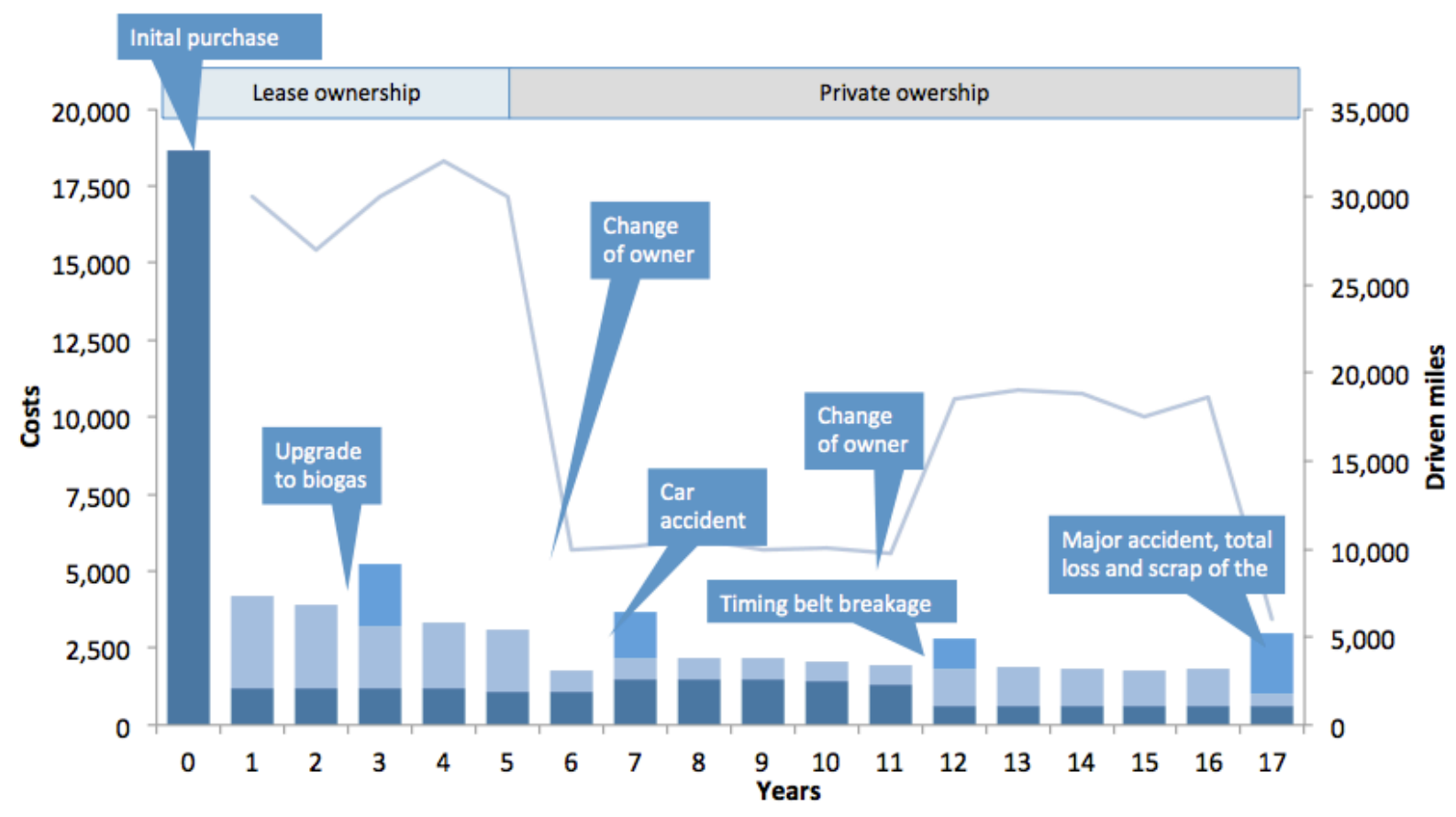

Figure 4. Cradle-to-grave lifecycle of a car
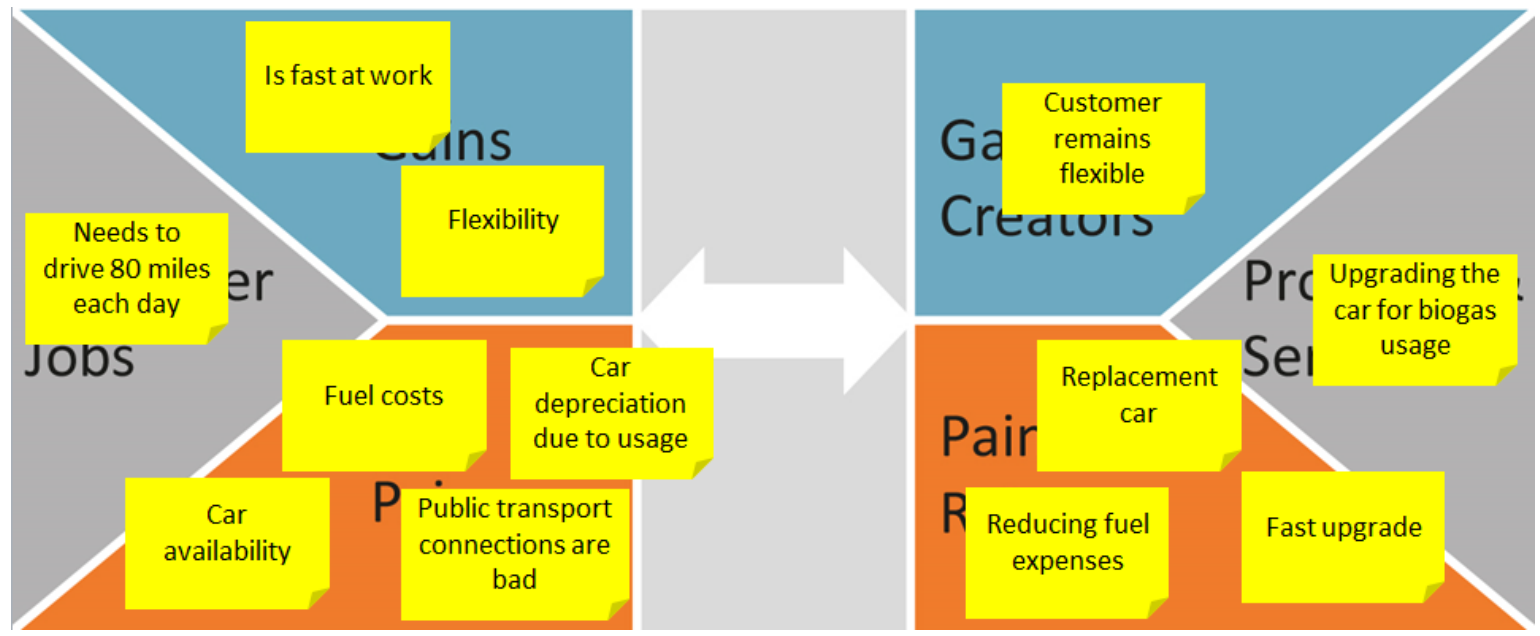

Figure 5. Value proposition design for a car engine upgrade/replacement 
Table 1. Overview of the two companies

\begin{tabular}{|c|c|c|}
\hline & David Brown Gears & Skan \\
\hline HQ & UK & Switzerland \\
\hline Sales & $\begin{array}{c}\text { 120GBP Total } / 70 \% \\
\text { service }\end{array}$ & $80 \mathrm{MCHF} / 20 \%$ \\
\hline Employees & 700 total / not given & $320 / 70$ services \\
\hline Segments & Industrial gear boxes & Medical and lab equipment \\
\hline $\begin{array}{c}\text { Workshop } \\
\text { focus }\end{array}$ & $\begin{array}{c}\text { 1. Gearboxes for coal } \\
\text { mills (engineered) }\end{array}$ & $\begin{array}{c}\text { 1. Isolators (engineered) } \\
\text { 2. Flow cabinets } \\
\text { (standardized) }\end{array}$ \\
\hline
\end{tabular}

\subsection{Visualization and Mixed Teams}

The workshop participants valued the structured visual tools to help them identify the services required for the operational life of the equipment. This finding was in agreement with the literature and the author's experience of running workshops. Prior to using the visual framework some participants had some difficulties describing the full range of services and their timing.

The use of mixed teams helps to provide a range of inputs from more technical to commercial ideas and is in agreement with Stickdorn and Schneider (2012). It provides an opportunity to service teams to describe customer value more clearly to their colleagues. More experience is required to identify the 'optimal' team mix for such workshops although the use of customers in the process was considered in a positive manner.

\subsection{Feedback on the Car Example}

The use of a car as a neutral example to allow the participants to become comfortable with the tools was a very helpful one. It provided a framework where the groups were able to grasp the concepts that are required:

- they identified the services and in some cases started to provide estimates of costs;

- with a detailed example they were also able to identify the customer value proposition both at a rational and on an emotional level.

\subsection{Feedback on the Company Specific Examples}

All teams were able to (with different levels of success) identify services, using the cradle-to-grave lifecycle that equipment owners and operators require to achieve the outcomes they were demanding. Some participants expressed their surprise in being close to the product and still being able to identify new services. The mixed teams used the cost drivers identified by Singh and Dunn (2008) to create groupings of associated tasks. This led to a visualization of the cradle-to-grave lifecycle similar to the Stockgi (2012) approach in Figure 2.

Interestingly, using the newly discovered activities one group started to construct a total cost of ownership model for a new 'rental' business model. The format of the cradle-to-grave lifecycle template provided a format where they could, as a team, visualize the necessary tasks and start to 'model' the costs. Both companies identified the equipment end-of-life phase as a potentially under-explored opportunity that may have benefits for both the customer and the supplier.

The importance of response with emergency access to spare parts came to light when discussing the customer value proposition. Using mixed teams helped the customer pains and gains to be clearly described for access to spare parts in an emergency: two teams agreed to redesign their processes. The objective of their redesign was to make it easier for the customer to contact them and then to ensure the appropriate information was exchanged, allowing the spare part to be more rapidly supplied with less risk of an error.

\subsection{Lessons Learnt}

The combination of the cradle-to-grave equipment lifecycle with the customer value proposition provided a visual tool around which the teams could discuss and improved communications amongst those present. At each workshop the following new ideas were discovered:

- $\quad$ end life opportunities - control of the second-hand market;

- $\quad$ upgrade opportunities - triggers for upgrades;

- $\quad$ service triggers that come from spare parts sales providing new sales opportunities.

The approach improved customer understanding by identifying:

- that some customers may have the initially purchased the wrong equipment;

- $\quad$ some customers need more assistance before they can purchase services;

- that the tools can help to understand the value propositions of today's services better;

- that customers in the same segment may experience different pains and gains (suggesting segmentation may not be correctly applied).

- that trigger point and events in the lifecycle are essential to identify appropriate points of time for new technology or services injections

\subsection{Integration of the Equipment Lifecycle with the Customer Value Proposition}

The lifecycle shows how the customer is using a specific product and when the costs occur and is in general agreement with the TOC/TOV models described by Ellram (1993), Singh and Dunn (2008) and others. The model also helps the supplier to understand what activities or tasks the customer encounters during the full lifetime of the equipment. Together with the value proposition canvas based on Osterwalder, et al. (2014) this approach provides a powerful methodology to identify key opportunities for services during the life of the equipment. It can help to identify areas where costs can be reduced or other service area where it is 
becomes possible to increase the perceived value of the service offering. An example for the car lifecycle with the customer value propositions overlaid is given in Figure 6 . The examples developed by both firms only considered single events and were considered confidential.

It was clear after the workshops that all of the tasks should have a customer value proposition associated with them and this is confirmed by Anderson et al. (2008) and Osterwalder, et al. (2014) who state that a customer value proposition should be created for all products and services. Before the workshops, it was considered that this might not be the case. However, the insights that it provides into customer drivers suggest that good practice would require this. Side discussions concerning the customer journey during the creation of the customer value proposition suggests that this may also be a useful tool to be employed where the customer interactions are either major pains or gains.

\subsection{Anticipated Extensions to this Methodology}

It is anticipated that by extending this methodology it should be possible to:
- estimate the total market value and identify the share of spend (or loyalty);

- forecast sales with timing of owner's spends;

- identify trigger points for conversions, modifications and updates;

- combine with the customer journey mapping.

\section{Conclusions}

The prototyping of the combination of the two tools was successful. Using the equipment lifecycle generated from the total cost of ownership in a visual way and combining it with Osterwalder, et al.'s (2014) customer value proposition was considered an interesting approach as a prototype. The workshops proved helpful for the firms, enabling them to identify new services and to understand why customers may require them. The three teams from the two companies were able to identify new ideas using this approach and understand how their customers might benefit from the new (or improved) services.

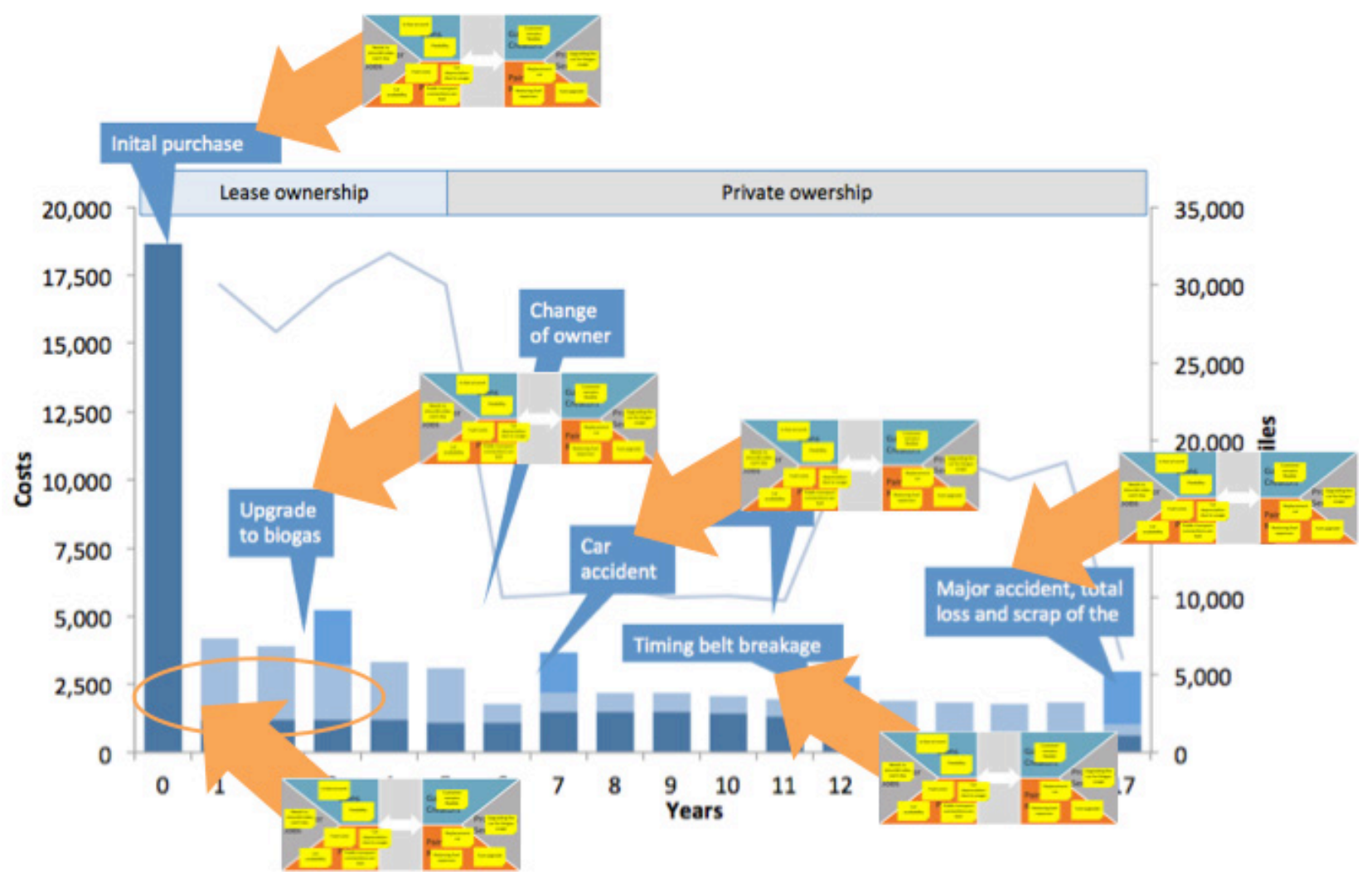

Figure 6. Every activity should have a customer value proposition associated with it 
The approach was experimental, but discussions with the teams and their managers suggested it proved useful in helping them to discover new/hidden services for their products. They appreciated especially the easy and intuitive use of the introduced tools. The visualization of the equipment lifecycle from the owner/operators perspective helped them to understand more the needs and real problems that occur. It was mentioned before that the presented approaches, such as the total cost of ownership, where perceived as complicated in the execution. However, the workshop showed that even without having a deeper and scientific understanding of such tools remarkable results can be achieved such as new service ideas. This was especially enabled by the easy sticky note canvas presentation of the methodology which enhanced a proactive group discussion and participant engagement. Interestingly, one group had an experienced financial controller within the team and the controller 'intuitively' began creating a simple financial model from the graph that his team were creating.

Discussions also suggested that there were potential improvements and extensions that could be developed without overly increasing the complexity of the process.

\section{Recommendations}

The tool should be improved and used in a number of additional workshops to provide it adds value to service development. Most important to understand are its limitations - when to use it and when not to use it. In particular, it is recommended to consider improvements to this methodology to.

The combined cradle-to-grave lifecycle and customer value proposition for a more of industrial products should be tested so that the wider applicability can be confirmed. In particularly here the minimal equipment lifecycle should be confirmed. For this long operation life equipment, the approach works well, however, for equipment with more rapid replacement cycles this may not be the case.

It is anticipated that that wider application of the data captured from the process could be made, including market valuation, sales forecasting, the share of spend and upgrade trigger points. The use of the data from the cradle-to-gravel lifecycle should be able to provide a solid foundation to strategic marketing and help the product development teams as well as sales to make more informed market-based decisions. However, this does require more development and testing to confirm this hypothesis.

Taking the strategic marketing hypothesis one stage further it could become possible to work with product development teams to understand the 'optimal' time to upgrade from the manufacturer's perspective. This could allow the optimal balance between upgrades to ensure that competitor remained always behind the manufacturer.

For touchpoints identified from the lifecycle analysis a detail customer journey should be considered. In particular, for the emergency response activities where emotional aspects can be very important for the parties involved although other touchpoints can also have a major impact on business relationships.

Osterwalder, et al. (2014) recommends reviewing the business models associated with delivery of each customer value proposition. This could be important as new business verse upgrades is common area where there can be conflict due to the different business drivers created by the different underlying business models and further analysis here could help confirm this expectation.

\section{Acknowledgements}

The authors would like to thank the Lucerne University of Applied Sciences and Arts, Switzerland for its support and the two companies David Brown Gears LTD and Skan AG.

\section{REFERENCES}

[1] Anderson, J. C., \& Narus, J. A. (1999). Business Market Management: Understanding, Creating, and Delivering Value. Journal of Business and Industrial Marketing. doi:10.1108/08858629910272265

[2] Anderson, J. C., Narus, J. A., \& Van Rossum, W. (2006). Customer value propositions in business markets. Harvard Business Review.

[3] Bains, T., Lightfoot, H. (2013). Made to serve: how manufacturers can compete through servitization and product-service systems. Wiley. ISBN: 978-1-118-58529-0.

[4] Cohen, M. A., Agrawal, N. \& Agrawal, V., 2006. Winning in the Aftermarket. Harvard Business Review, May, pp. 129-138.

[5] Ellram, L. (1993). Total cost of ownership: Elements and implementation. International Journal of Purchasing and Materials Management, 29, 3. doi:10.1111/j.1745-493X.1993.tb00013.x

[6] Fischer, T., Gebauer, H., Fleisch, E. (2012). Service Business Development: strategies for value creation in manufacturing firms. Cambridge University Press. ISBN: 978-1-107-02245-4.

[7] Hurkens, K., \& Wynstra, F. (2004). The concept "Total Value of Ownership": A case study approach, 51-62.

[8] Osterwalder, A., Pigneur, Y., Bernarda, G., Smith, A. Papadakos, T. (2014) Value Proposition Design: How to Create Products and Services Customers Want. Wiley. ISBN: 978-1-118-96805-5

[9] Neely, A., 2007. The Servitization of Manufacturing: an Analysis of Global Trends. European Operations Management Association Conference, 20 June, pp. 1-10.

[10] Singh, H., \& Dunn, W. H. (2008). Total asset management. Military Engineer, 100, 57-58.

[11] Stickdorn, M., Schneider J. (2012). This is Service Design 
Thinking: Basics, Tools, Cases. BIS. ISBN: [13] Wynstra, F., \& Hurkens, K. (2005). Total Cost and Total 978-90-6369-279-7. Value of Ownership Total Cost of Ownership: Definition and Objective. In Perspektiven des Supply Management (pp. 463-

[12] Asset Management | Stockgi. (2012). Retrieved April 7, 2015, from http://stockgi.com/?page_id=23\&lang=en 482). doi:10.1007/b138510 